\title{
IDENTIFICANDO MANIFESTAÇÕES PATOLÓGICAS: O CASO DO "PALACETE DOS PEREIRAS" - PRINCESA ISABEL - PB
}

\author{
DE PAULO, GIOVANNA S. \\ Estudante \\ IFPB-PI \\ Paraíba; Brasil \\ giovanna.silva@academico.ifpb.edu.br \\ AQUINO, SAMUEL M. \\ Estudante \\ IFPB-PI \\ Paraíba; Brasil \\ samuel.medeiros@academico.ifpb.edu.br
}

\author{
DOS SANTOS, MARCIELLY A. \\ Estudante \\ IFPB-PI \\ Paraíba; Brasil \\ marcielly.araujo@academico.ifpb.edu.br \\ SOUSA, NÍLBERTE M. \\ Professor \\ IFPB-PI \\ Paraíba; Brasil \\ nilberte.muniz@hotmail.com
}

\author{
ADVINCULA, CHYARA C. B \\ Professor \\ IFPB-PI \\ Paraíba; Brasil \\ chyara.advincula@ifpb.edu.br
}

\section{RESUMO}

As edificações possuem a capacidade de criar a identidade de determinado povo ou tempo histórico e por isso mesmo, devem ser preservadas. Um exemplo disso seria o "Palacete dos Pereiras" localizado em Princesa Isabel-PB. Esta edificação foi construída na década de 1920 no estilo eclético que acomoda mosaicos austríacos e imensos janelões. O prédio foi tombado pelo Instituto do Patrimônio Histórico e Artístico do Estado da Paraíba, em 2005, por meio do processo 0281/04, que deveria assegurar a preservação do edifício. Desta forma o trabalho objetivou realizar uma vistoria para identificar as manifestações patológicas existentes na edificação. Para tanto, foi realizadas visitas em in loco para listar os danos existentes, foram feitos registros fotográficos para posteriores análises, e a realização de medições através da utilização de trenas e paquímetros. Observou-se que a edificação apresenta um grande número de manifestações patológicas que acabam trazendo prejuízo a estrutura. Com o agravante de que o patrimônio é tombado e deveria ter uma constante manutenção para garantir a preservação do espaço histórico.

PALAVRAS CHAVE: Preservação, Patrimônio, Manifestações.

\section{ABSTRACT}

Buildings have the ability to create the identity of a particular people or historical time and therefore must be preserved. An example of this would be the "Pereiras Palace" located in Princess Isabel-PB. This building was built in the 1920s in eclectic style that accommodates Austrian mosaics and immense windows. The building was listed by the Institute of Historical and Artistic Heritage of the State of Paraiba in 2005, through process 0281/04, which was supposed to ensure the preservation of the building. Thus, the work aimed at carrying out a survey to identify the pathological manifestations existing in the building. To this end, on-site visits were made to list the existing damages, photographic records were made for further analysis, and measurements were performed through the use of measuring tape and calipers. It was observed that the building presents a large number of pathological manifestations that end up causing damage to the structure. With the aggravating factor that the heritage is listed and should have a constant maintenance to ensure the preservation of the historical space.

KEYWORDS: Preservation; Heritage; Manifestations. 


\section{INTRODUÇÃO}

As construções históricas são bens materiais com alto valor cultural que fazem parte do registro histórico que resguarda uma época do desenvolvimento de uma determinada sociedade, e que necessita de intervenções rotineiras de manutenção com vista à preservação da integridade estrutural destas construções (CAVALCANTE et. al., 2016).

A manutenção constante dessas edificações é de extrema importante para que possa manter o patrimônio histórico nas mais perfeitas condições possíveis. Entretanto, não é essa a realidade que se pode observar quando o assunto é preservação das edificações históricas.

De acordo com Barbosa (2017), a preservação do patrimônio de edifícios histórico-culturais encontra atualmente uma série de obstáculos decorrentes da escassez de recursos e da ausência de investimentos nos serviços de manutenção. Contudo, é notório que a restauração e a conservação possibilitam a transmissão às gerações futuras dos valores culturais de uma determinada sociedade, tornando-se imprescindíveis as ações de preservação do patrimônio histórico.

Nas edificações históricas, devido a falta de manutenção e o abandono é fácil perceber a presença das manifestações patológicas que acabam trazendo grandes prejuízos a estrutura do imóvel. Entre essas manifestações as mais frequentes são as fissuras, manchas de umidade, corrosão das armaduras, agentes biológicos e ineficiência dos sistemas de drenagem.

Segundo OLIVEIRA (2012) Fissuras, trincas e rachaduras são manifestações patológicas das edificações observadas em alvenarias, vigas, pilares, lajes, pisos entre outros elementos, geralmente causadas por tensões dos materiais. Se os materiais forem solicitados com um esforço maior que sua resistência acontece a falha provocando uma abertura, e conforme sua espessura será classificada como fissura, trinca, rachadura, fenda ou brecha. Segundo a literatura vigente, fissuras são classificadas de acordo com a profundidade e características da abertura, assumindo nomes diferentes. De acordo com Civilização Engenharia (2018) as fissuras são aberturas estreitas e alongadas na superfície de um material. Geralmente são de gravidade menor e superficial.

Já a Infiltração é o processo no qual a água da superfície ou proveniente de chuvas que atravessam a estrutura da edificação. Tais problemas são graves e de difícil solução, tais como: Prejuízos de caráter funcional da edificação, desconforto dos usuários e em casos extremos podem afetar a saúde dos moradores, danos em equipamentos e bens presentes nos interiores das edificações e diversos prejuízos financeiros (CIVILIZAÇÃO ENGENHARIA, 2018). A infiltração constante provoca a desagregação do revestimento, com pulverulência ou formação de bolor em locais onde não há incidência com o sol (SOTANA et. al., 2012).

Conforme a NBR 15575 (2013), prescreve que a água é o principal agente de degradação de um amplo grupo de materiais de construção, estando presente no solo, na atmosfera, nos sistemas e procedimentos de higiene da habitação. $\mathrm{O}$ excesso de umidade pode causar vários transtornos para edificação, pode danificar a estrutura e o revestimento do imóvel. Já para saúde dos moradores pode causar doenças respiratórias e alergias devido aparecimento de bolores e mofos.

A corrosão é frequentemente relacionada à presença de teores críticos de íons de cloreto no concreto ou no abaixamento do seu $\mathrm{pH}$ devido às reações com compostos presentes no ar atmosférico, especialmente o dióxido de carbono (ARAÚJO, 2013).As principais causas do problema são as falhas no processo de concretagem da estrutura, por exemplo, no lançamento ou adensamento do concreto. Algumas vezes, no entanto, a patologia pode ser causada por erro no detalhamento da armadura (FIGUEROLA, 2006). 
O destacamento de pisos cerâmicos. As fissuras e deslocamento podem ser causados por fissuras ocorridas na interface do revestimento com estrutura, falta de reforço no substrato, falta de juntas de controle, preenchimento inadequado de juntas de colocação, falta de argamassa de assentamento no verso das placas, não observação dos limites em aberto da argamassa no verso das placas, não assentamento(BACELOS, 2011).

Agentes biológicos, Para que uma planta possa se desenvolver, para que haja surgimento de vida, é necessária a presença de luz e água.A primeira, erroneamente confundida com fungos, é o surgimento e proliferação de pequenas algas em fissuras ou em concretos muito porosos e é provocada pela umidade nas paredes, decorrentes ou em razão de infiltrações internas ou devido à ineficaz impermeabilização da estrutura (PLAISANT, 2015).

Sistema de drenagem é o nome que se dá a uma série de estruturas que são instalados em um determinado local com o intuito de reter, tratar e transpor águas pluviais. Tais sistemas podem ser públicos, na forma de bocas de lobo e sarjetas, por exemplo, podem ser instalados em residências, como casas e apartamentos, ou mesmo em edifícios comerciais, como fábricas e lojas, podendo ter uma estrutura simples, que concentra apenas o básico, ou complexa, que é capaz de coletar, tratar e distribuir a água para diversos pontos distintos.

Diante disso, este trabalho tem como objetivo identificar as manifestações patológicas existentes em uma edificação histórica, para que possa abordar as melhores maneiras de correção dessas manifestações patológicas para que não se tenha nenhum prejuízo ao patrimônio que apresenta grande importância para a preservação das memórias de uma região.

\section{2. ÁREA DE ESTUDO}

Falar em preservação da memória de uma dada sociedade tem ligação direta com o conceito de Patrimônio Cultural o qual, de acordo como artigo 206 da Constituição Federal de 1988, é caracterizado como bens "de natureza material e imaterial, tomados individualmente ou em conjunto, portadores de referência à identidade, à ação, à memória dos diferente grupos formadores da sociedade brasileira". Tomando como base essa conceituação torna-se imprescindível expor o estudo de caso do "Palacete dos Pereiras" o qual foi construído na década de 1920 e está intimamente relacionado ao grupos políticos que governavam a Paraíba naquele momento. Sendo assim, julga-se relevante expor o contexto histórico da cidade de Princesa Isabel, pois este justifica o valor cultural da edificação.

Nesse sentido, observa-se que cidade de Princesa Isabel-PB teve grande destaque devido a Revolta de Princesa em 1930, a qual extrapolou os limites e ensejou a chamada "Revolta de 30". Tendo em vista o peso histórico-político desse acontecimento, essa Revolta foi um movimento que culminou na criação do "Território Livre de Princesa", o qual passou a obedecer somente as leis federais, desconsiderando as normativas estaduais. Desse modo, Princesa entra em guerra contra o presidente do Estado João Pessoa, justamente no momento em que a cidade passava pelo auge de seu desenvolvimento econômico, político, social e cultural. A cidade crescia a passos largos para criar uma atmosfera moderna a exemplo dos vários casarões construídos para este fim. Um desses casarões é o "Palacete dos Pereiras".

A edificação conhecida como "Palacete dos Pereira" situada em Princesa Isabel - Paraíba foi construída em 1923 por Epitacinho, sobrinho de Epitácio Pessoa. Este comandava a oligarquia dominante no Estado da Paraíba. A família Pessoa era dividida em dois grupos. Em Umbuzeiro vivia os Pessoa Cavalcanti de Albuquerque e os da Silva Pessoa Santiago, já no Recife residia os Pessoa de Queiroz (GOMES, 2018). No ano de 1922 ocorre um conflito familiar, associado ao assassinato do médico José Bandeira de Mello Filho, marido de Clarice Pessoa Santiago. Um crime passional cometido por Epitácio Sobrinho Pessoa de Queiroz. Este, para evitar sua prisão foge para Princesa e é recebido pelo Coronel José Pereira (LEWIN, 1993). 
Ao chegar na cidade toma providências para construção do palacete. Para isso, contratou o artesão e construtor José Ferreira Dias, conhecido por "FERREIRÃO". Epitacinho residiu neste edifício até o julgamento final do processo crime. Findo este período volta para o Recife e doa sua residência a família Pereira. Em 1930, ano da Revolta de Princesa, o casarão serviu de hospital de sangue para os combatentes feridos nas batalhas contra o governo do estado (MEDEIROS, 2017).

Alguns anos após a Revolução de 1930, a família Pereira passa a residir no edifício, o qual passou por alterações tais quais: “ [...] terraços, sala para refeições, apartamentos, ampliação da cozinha, construção de um quarto de despejo e o melhoramento nos sanitários [...] (MEDEIROS, 2017) (Figura 01). Com o passar dos anos seus salões testemunharam bailes e reuniões, nas quais foram tomadas importantes decisões da vida política paraibana. Dada sua importância política e arquitetônica o prédio foi tombado pelo IPHAEP Instituto do Patrimônio Histórico e Artístico do Estado da Paraíba - por meio do processo 0281/04. Todavia, por falta de revitalização morre aos poucos a memória daqueles que fizeram de Princesa uma das cidades mais importantes da Paraíba.

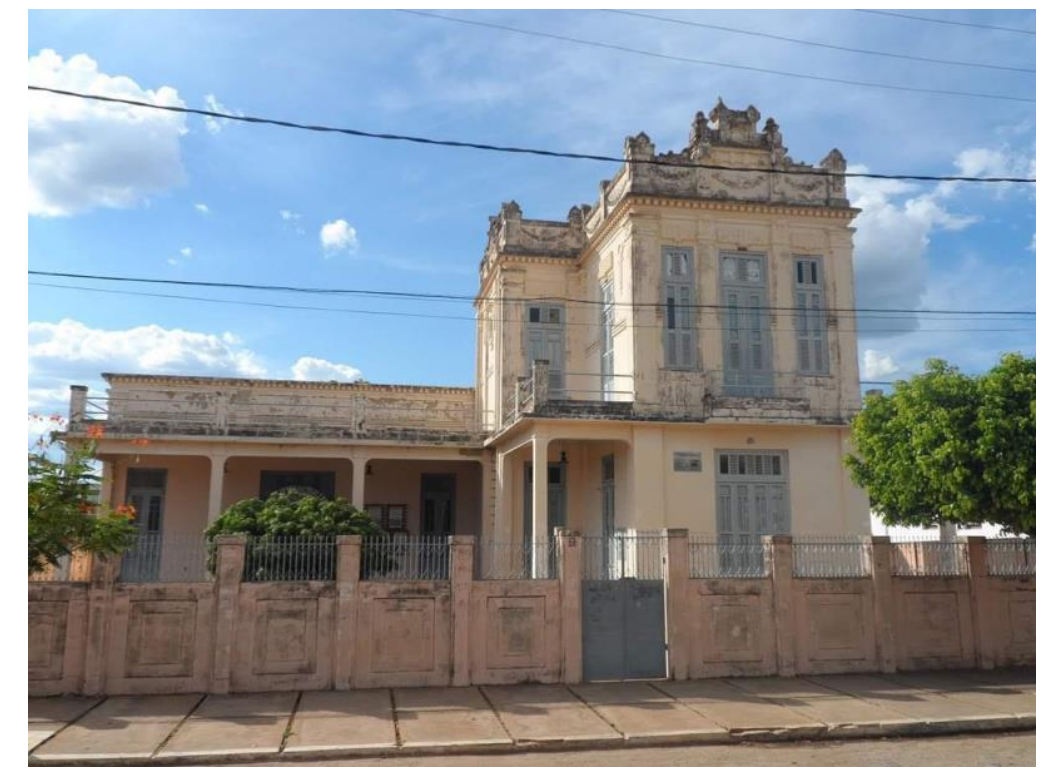

Figura 01: Fachada frontal do "Palacete dos Pereira"

\section{PROCEDIMENTOS METODOLÓGICOS}

A metodologia adotada foi constituída de uma pesquisa in loco, com o intuito de identificar as manifestações patológicas existentes em uma edificação histórica situada em Princesa Isabel-PB, propondo as melhores maneiras de correção dessas manifestações. Para tanto, foram realizados registros fotográficos e utilizados equipamentos de medições.

Objetivando-se o registro das manifestações presentes na edificação, foram confeccionadas as plantas baixa e de pav. superior (Figura 02 e Figura 03), respectivamente. A representação da fachada do palacete também foi confeccionada (Figura 04) para melhor entendimento da construção e apreciação de sua arquitetura. Estão indicadas nas plantas o posicionamento de cada manifestação patologica, encontrada no palacete, cada uma referenciada por uma numeração em algarismos romanos, seu simbolismo é expresso em forma de tabela. 

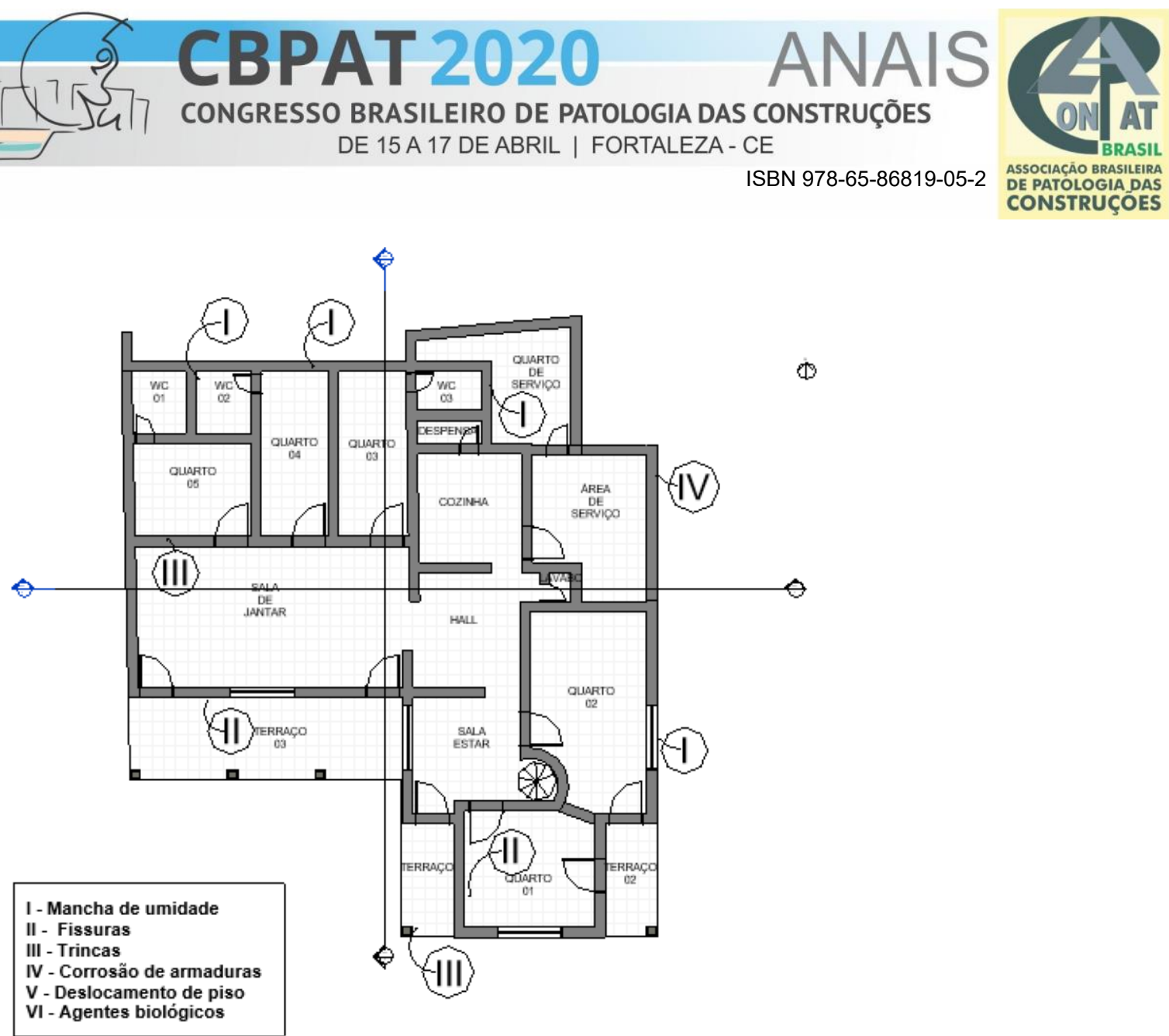

Figura 02: Planta baixa com as representações patológicas.

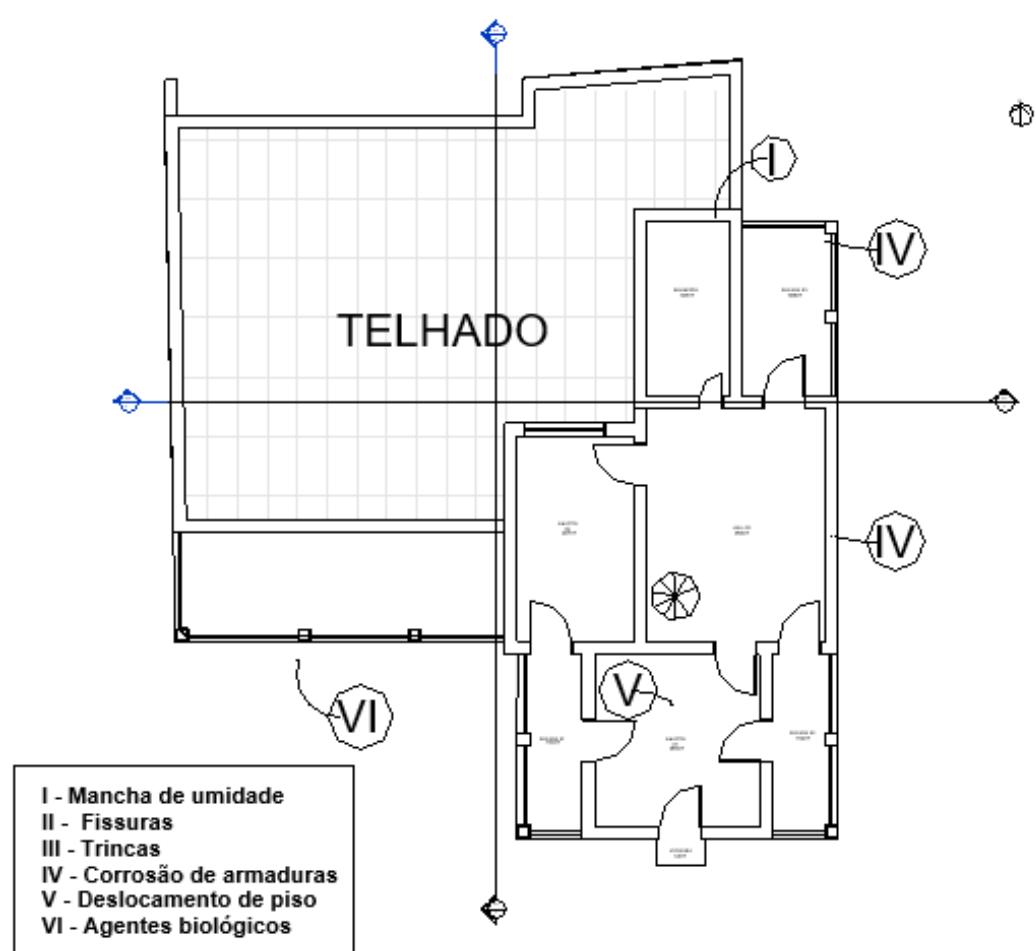

Figura 03: Planta do Pav. Superior com as representações patológicas. 


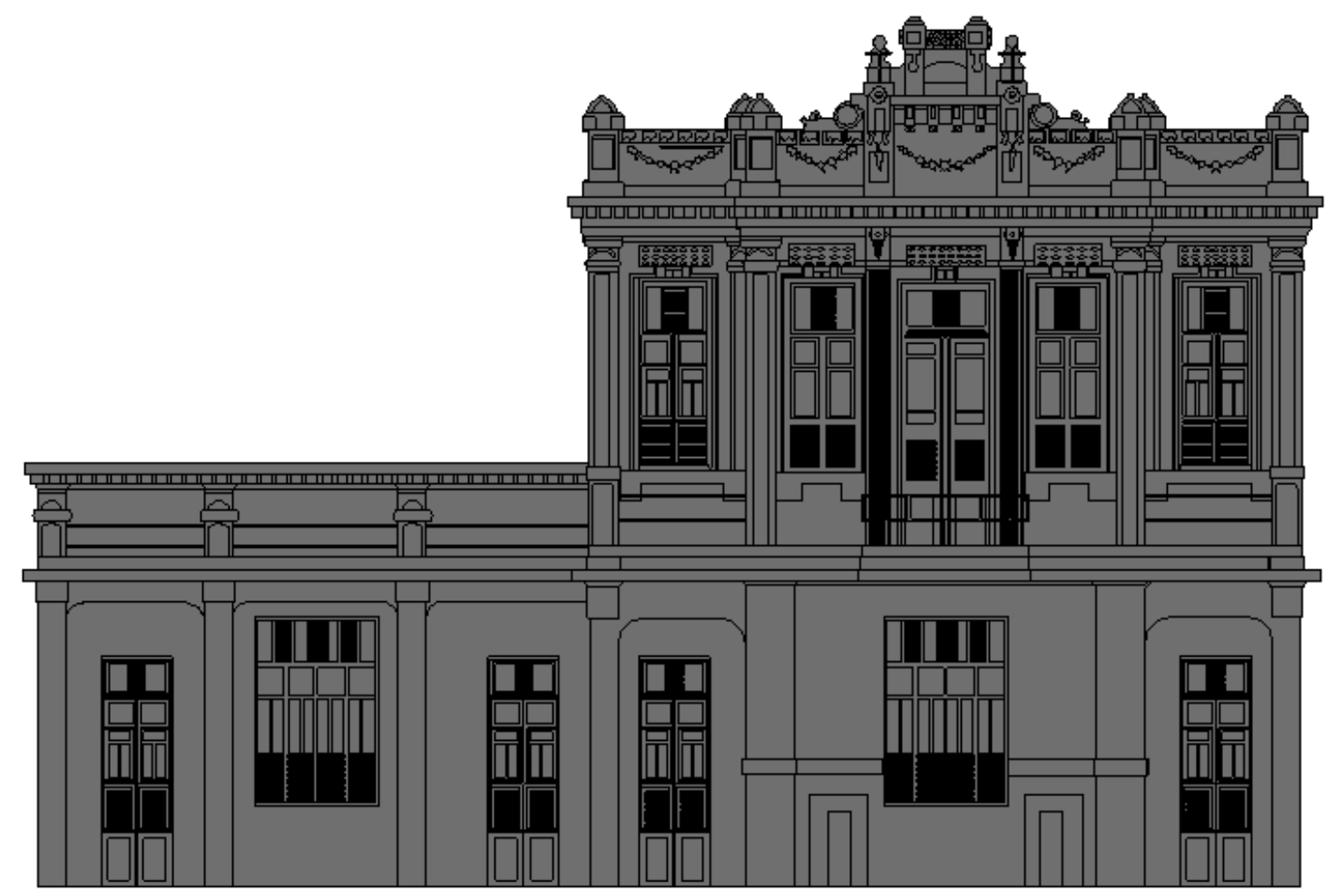

Figura 04: Representação da fachada frontal da edificação.

\section{AVALIAÇÃO E DIAGNÓSTICO DAS MANIFESTAÇÕES PATOLÓGICAS NA EDIFICAÇÃO}

O fator tempo e a falta de manutenção potencializam o surgimento de manifestações patológicas. Entre as manifestações encontradas têm-se: Fissuras, infiltrações e manchas de umidade, corrosão das armaduras, deslocamento de piso, agentes biológicos e ineficiência dos sistemas de drenagem.

\subsection{Fissuras}

Foram encontradas na residência estudada além de fissuras (Figura 05) e várias trincas como mostra a Figura 06 e figura 07 que superaram os $3 \mathrm{~mm}$. Estas manifestações patológicas geram um alto risco para estrutura, encontrando-se uma enorme quantidade dessas manifestações no "Palacete dos Pereira".

Constatado esse tipo de manifestação patologica, é hora de listarmos as seguintes recomendações para solucionar o problema, em caso de elementos menos afetados, aplicação de argamassa polimérica nas fissuras. Em elementos moderadamente afetados pode ser feito o alargamento da fissura e aplicação de argamassa polimérica na superfície. Em elementos severamente afetados, como trincas devem ser feito o apicoamento e injeção de argamassa polimérica ou graute. 


\section{СВРAT 2020

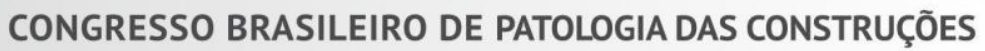 DE 15 A 17 DE ABRIL | FORTALEZA - CE}

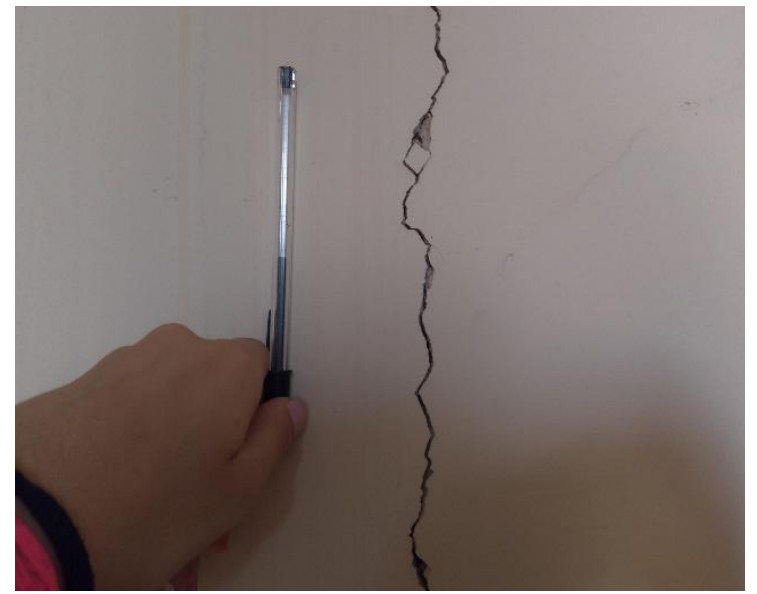

Figura 05: Fissura na fachada frontal (TERRAÇO 03)

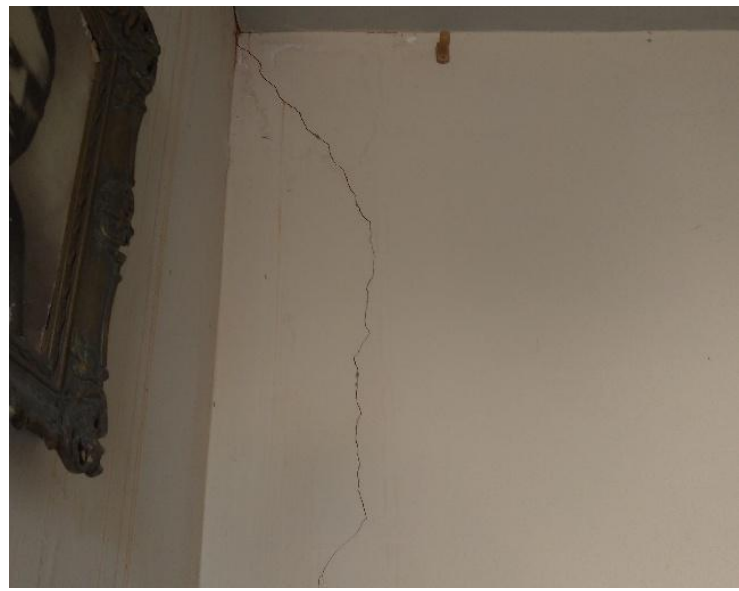

Figura 06: Fissuras internas (SALA DE JANTAR)

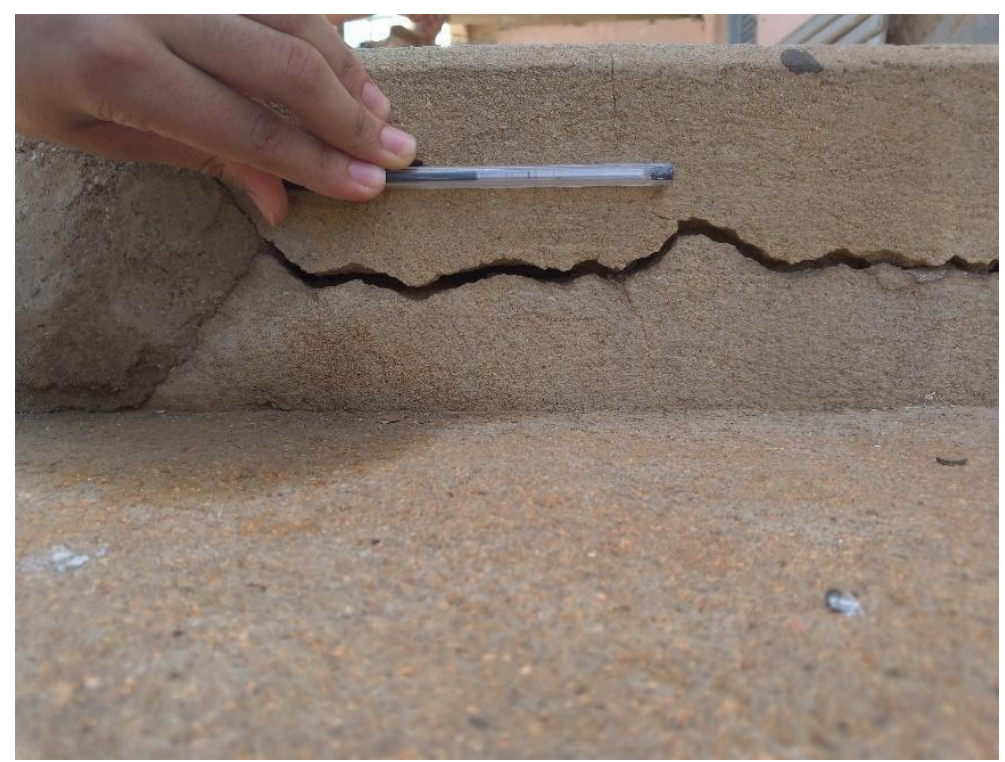

Figura 07: Trincas (LAVANDERIA)

\subsection{Manchas de umidade}

Observou-se que o telhado da edificação está com telhas quebradas e afastadas (Figura 08) o que facilita a entrada de águas pluviais, provocando o empoçamento da laje. Há também áreas em que as lajes não estão protegidas por um telhado e apresentam uma deficiência na sua drenagem (Figura 09), o que contribui para o acúmulo de águas pluviais que gradativamente infiltram nas lajes e ocasionam as manchas e umidade.

Decorrente disso, foram observados diversos pontos com manchas de umidades na edificação (Figura 10), o que mostra que o reparo no telhado e uma melhoria no sistema de drenagem das lajes são de extrema importância e devem ser realizadas o quanto antes. Uma vez que a presença de umidade é o fator que acarreta diferentes tipos de manifestações patológicas. 


\section{CBPAT 2020

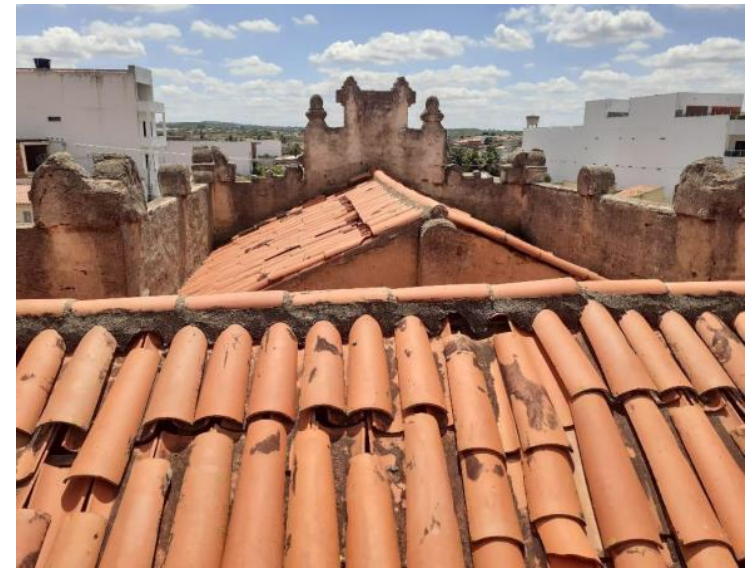

Figura 08: Telhado do danificado "Palacete dos Pereira"

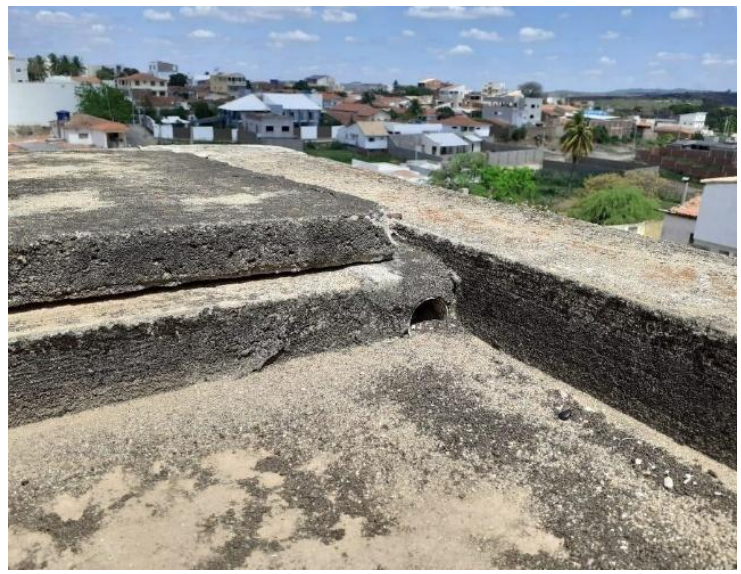

Figura 09: Falha no sistema de drenagem (LAJE DA CAIXA D'ÁGUA)

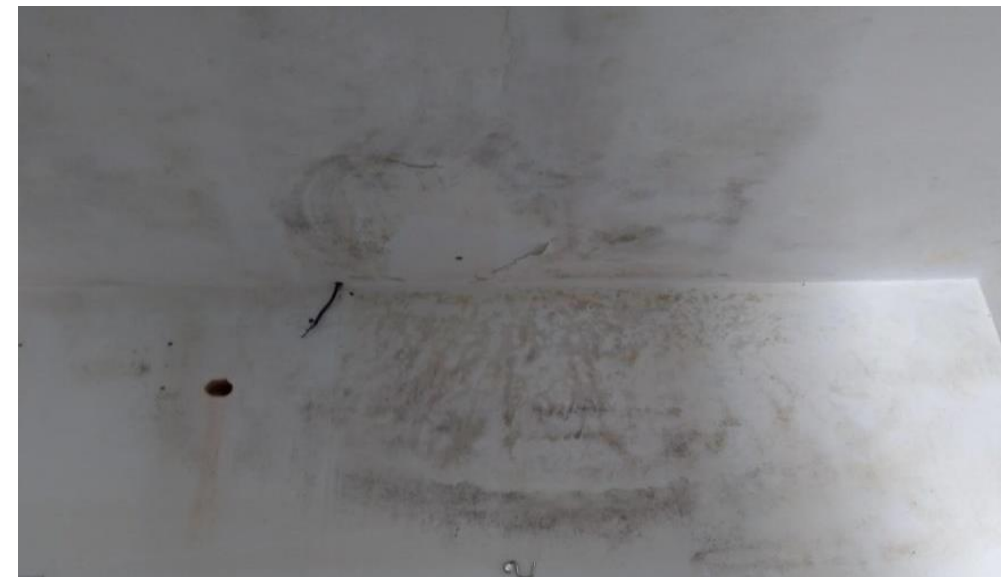

Figura 10: Manchas de umidade (QUARTO 02)

\subsection{Corrosão das armaduras}

Durante a inspeção notou-se a presença desta manifestação patologica em algumas vigas e lajes da edificação (Figura 11), é preocupante devido ao fato deste tipo de patologia comprometer a resistência da estrutura, a longo prazo essa despassivação do aço pode ocasionar o desmoronamento da estrutura.

Após constatar a presença deste tipo de patologia o procedimento padrão para a recuperação das áreas contaminadas por corrosão das armaduras consiste em retirar todo o concreto deteriorado até que se obtenha a exposição completa de uma superfície do concreto sã e íntegra. Todo o produto de corrosão aderido às superfícies das barras das armaduras deverá ser completamente retirado antes que sejam colocados os materiais de reparo. Viabilizam-se os procedimentos de eliminação da corrosão baseados em limpeza rigorosa, utilizando lixas e mesmo jatos de areia ou limalhas. 

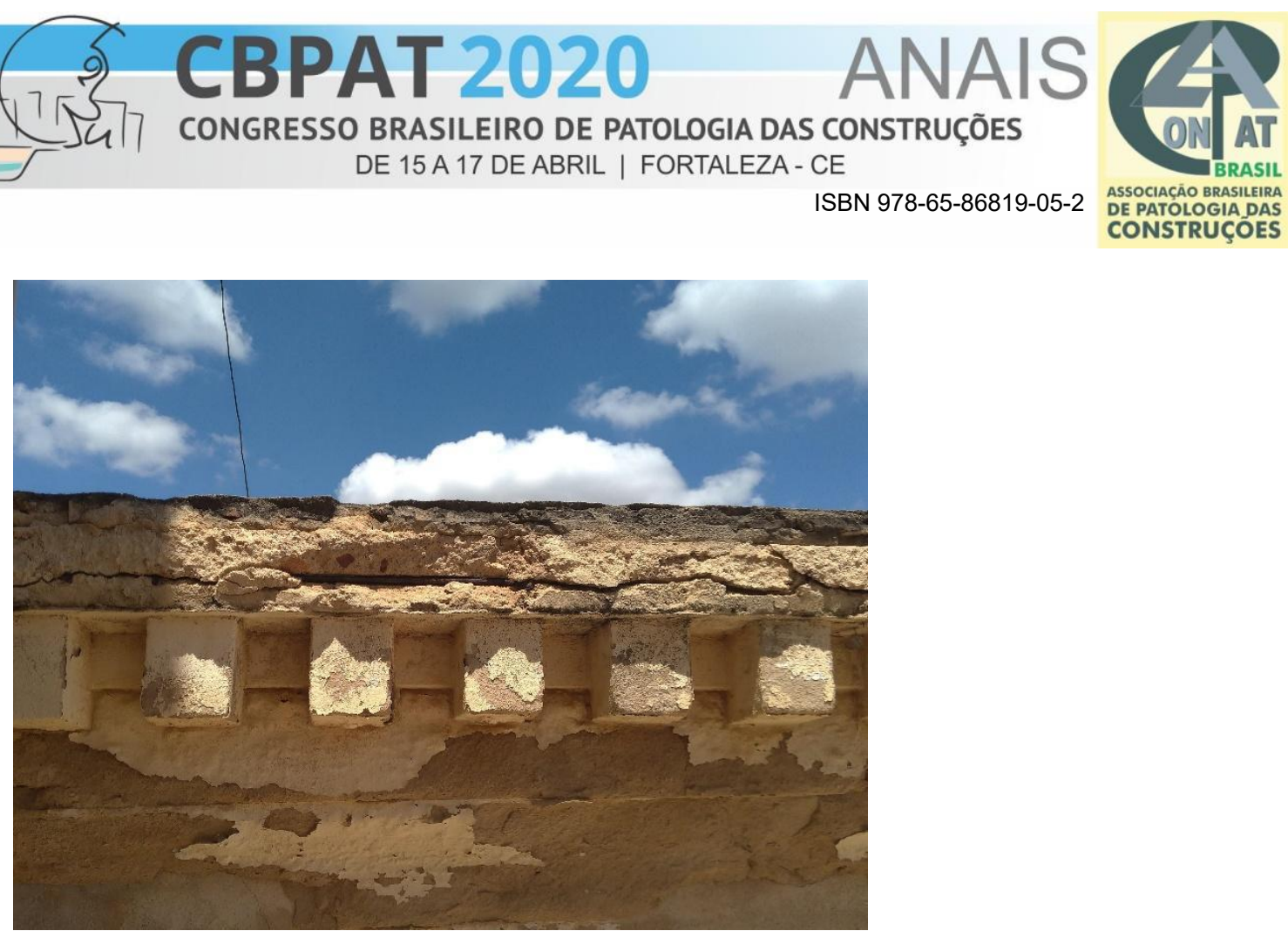

Figura 11: Corrosão presente na armação (SACADA 03)

\subsection{Destacamentos de piso}

Antes da reforma na década de 80, o piso era de madeira e com o passar do tempo ele foi se desgastando, com isso, foi feito um piso de concreto revestido com cerâmicas. Como o quarto tem uma pequena área livre que possibilita expor o piso interno a intempéries externos e isso pode ter provocado o levantamento das placas cerâmicas (Figura 12).

Diante do referido problema, é necessário ações interventivas, como o nivelamento e substituição dos pisos, para evitar a entrada de água no cômodo recomenda-se a colocação de um sistema de barragem da água das chuvas na porta, podendo ser de plástico ou borracha. O simples nivelamento do piso já amenizaria a entrada de água no cômodo.

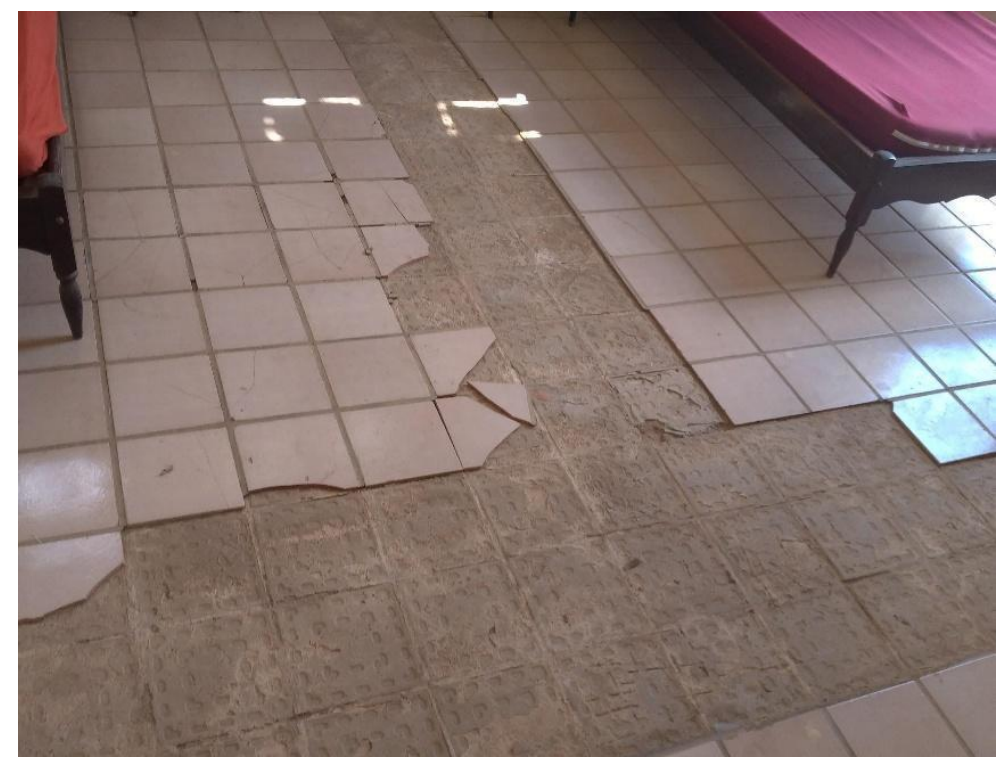

Figura 12: Desplacamento de pisos cerâmicos( QUARTO 07) 


\subsection{Agentes biológicos}

A vegetação se desenvolve onde encontra um substrato adequado ao seu crescimento. Um exemplo de vegetação não intencional que age diretamente sobre a edificação é aquela que cresce devido ao acúmulo de pó e matéria orgânica na edificação, causando danos estruturais, desagregação no revestimento e fissuras que constituirão um caminho direto para a umidade. Observa-se o crescimento de uma planta saindo do interior da parede da edificação (Figura 13).

A solução adequada para este problema é a retirada imediata da vegetação, averiguação do estado da alvenaria e combater as fissuras que proporcionam esse o surgimento desse tipo de manifestação patologica.

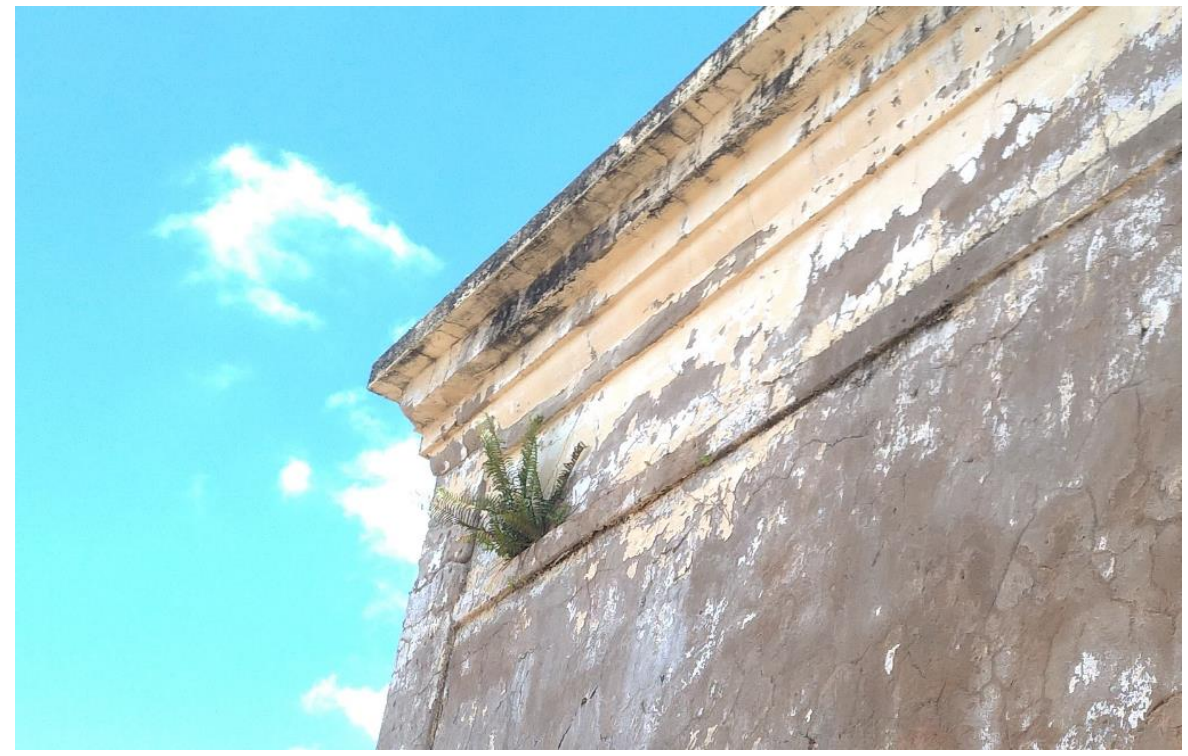

Figura 13: Vegetação saindo da parede (CAIXA D`ÁGUA)

\section{CONCLUSÃO}

A manutenção de edifícios possui um significado abrangente tanto economicamente quanto socialmente, dáse por manutenção segundo a normalização brasileira "o conjunto de atividades a serem realizados para conservar ou recuperar a capacidade funcional da edificação e de suas partes constituintes, de atender as necessidades e segurança dos seus usuários. “

O diagnóstico das manifestações patológicas foi de grande importância, pois, é possível planejar as atividades de recuperação, restauração, dentre outras. As manifestações encontradas no "Palacete dos Pereiras" indicam os problemas que vêm surgindo através dos tempos, sem manutenção ou preservação o edifício se encontra em estado deplorável, o descaso com o patrimônio histórico mais ilustre da nossa região vai contra as diretrizes do Decreto-Lei de $\mathrm{N}^{\circ} 25$, de 1937, sete anos após a revolução de 30, a edificação estudada reflete a realidade de uma história esquecida e abandonada. A estrutura da residência aqui descrita guarda um verdadeiro tesouro histórico pouco comum em nossa região, é de se admirar uma obra com traços tão finos, em meio a um cenário tão rústico. A preservação do Palacete dos Pereira deve ser de interesse público, pois as paredes da edificação guardam consigo as memórias de um povo esquecido após a revolução de 30.

Procurando uma maneira de reconstituir a glória do palacete, foi instituído que o prédio servirá como sede da mais nova academia de letras de Princesa Isabel, que têm por objetivo incentivar ações de cultura e 
preservação da história do município, visando um engrandecimento dos fatos históricos ocorridos na cidade. O surgimento desse órgão nas dependências do palacete, faz brotar a esperança de uma revitalização da edificação. Diante de utopias, atualmente apenas conseguimos vislumbrar um palacete restaurado em nosso imaginário. Basta apenas esperar e deixar o tempo revelar o que de fato acontecerá.

\section{REFERÊNCIAS}

ARAÚJO, A. et al., Monitoramento da corrosão em estruturas de concreto: sensor de umidade, de taxa de corrosão e de fibra óptica. São Paulo: Téchne 195. p.62-72. 2013.

ASSOCIAÇÃO BRASILEIRA DE NORMAS TÉCNICAS: NBR 5674. (1999). Manutenção de Edifícios Procedimentos.

AVALINO, T. J. R.Pessoa e máscaras: poder local, família e tradição.2014. 32f. Trabalho de Conclusão de Curso (Graduação em História) - Universidade Estadual da Paraíba, Campina Grande, 2014.

BARBOSA, R. O projeto de conservação preventiva do Museu Casa de Rui Barbosa. Rio de Janeiro.2017.

BERTOLINI, L. Materiais de construção. São Paulo: Oficina de texto. 2010. 415p

BRITO, Leandro Dussarrat. Patologia em estruturas de madeira: metodologia de inspeção e técnicas de reabilitação. 2014. 502 f. Tese (Doutorado) - Curso de Engenharia, Engenharia de Estruturas, Universidade de São Paulo, São Carlos, 2014.

CAVALCANTE, F. P. Efeito da adição dos óleos de ricinuscommunis e linususitatissimum nas propriedades reológicas do cimento asfáltico de petróleo puro e modificado. 2016. 273 f. Tese (Doutorado em Ciência e Engenharia de Materiais), Programa de Pós-graduação em Ciência e Engenharia de Materiais, Centro de Ciências e Tecnologia, Universidade Federal de Campina Grande - Paraíba - Brasil, 2016.

CIVILIZAÇÃO $\quad$ ENGENHARIA. 4 abr. $2018 . \quad$ Disponível em: <https://civilizacaoengenheira.wordpress.com/>. Acesso em: 19 dez 2019.

CÓIAS, V. Inspecções e Ensaios na Reabilitação de Edifícios. Lisboa, IST PRESS. 2006.

CORSINI, R. Trinca ou fissura?.São Paulo: Téchne. 160, p., jul. de 2010. Disponível em: <http://techne.pini.com.br/engenharia-civil/160/trinca-ou-fissura-como-se-originam-quais-os-tipos-2854881.aspx>. Acesso em 06 nov. 2016.

FIGUEROLA, Valentina. Revestimento de Argamassa. Equipe de Obra, São Paulo, ed.8, nov/dez. 2006. Disponível em: < http://www.equipedeobra.com.br/construcaoreforma/8/artigo36169-1.asp>. Acesso em: 19 $\operatorname{dez} 2019$.

FÓRUM DA CONSTRUÇÃO. Disponível em: - http://www.forumdaconstrucao.com.br/. Acessado em: 12.Nov. 2019

INSTITUTO DE PESQUISAS TECNOLÓGICAS. Corrosão em construção civil. Brasil. Disponível em: <http://www.ipt.br/solucoes/272-corrosao_em_construcao_civil.htm>. Acesso em: 06 nov. 2016 
LEWIN, L. Política e parentela na Paraíba: um estudo de caso da oligarquia de base familiar. 1993. p 432. Rio de Janeiro. 1933.

MINISTÉRIO DA SAÚDE, Secretaria de Ciência, Tecnologia e Insumos Estratégicos, Departamento do Complexo Industrial e Inovação em Saúde. Classificação de risco dos agentes biológicos. 2017. 3. ed. 48 p. Brasília. 2017.

OLIVEIRA, M. Fissuras, trincas e rachaduras causadas por recalque diferencial de fundações. Belo Horizonte: Téchne. 160, p... jul. de 2012. Disponível em: < https://repositorio.ufmg.br/bitstream/1843/BUOS9A3GCW/1/monografia_esp_2012_1_th.pdf>. Acesso em: 19 dez. 2019

PLAISANT, A. M. Patologias biológicas - Tratamento de vida vegetal nos edifícios históricos do Rio de Janeiro. IV CIRMARE. Rio de Janeiro. 2015.

SHIRAKAWA, Márcia Aiko; MONTEIRO, Maria Beatriz B.; SELMO, Silvia M. S.; CONCOTTO, Maria Alba. Identificação de fungos em revestimentos de argamassa com bolor evidente. In: SIMPÓSIO BRASILEIRO DE TECNOLOGIA DAS ARGAMASSAS, 1995, Goiânia. Anais... Goiânia: ANTAC, 1995.

SOTANA, A. F. Patologia das estruturas, pisos, concreto armado e revestimentos. 2012. 33 f. Trabalho apresentado à disciplina de Construção Civil II, Chapecó/SC, 2012. 